\title{
Heartbeat: heart failure induced by cancer therapy
}

Heart failure (HF) is the most common and serious cardiovascular complication of cancer therapy. As succinctly stated in an editorial by Lyon, 'Success in the diagnosis and treatment of many cancers has resulted in a growing population of people living either cured of cancer or with their cancer controlled as a chronic disease by long-term treatment. This success story in modern medicine has created a new problem with some survivors developing cardiovascular disease (CVD) as a result of their cancer treatment.' 1

CVD outcomes in patients with HF induced by cancer therapy are addressed in this issue of Heart. ${ }^{2}$ Comparing 75 patients with HF induced by cancer therapy (anthracycline chemotherapy or chest irradiation) to 894 patients with HF due to other causes, cancer therapy patients were younger, had fewer CVD comorbidities and a higher left ventricular (LV) ejection fraction but more severe LV diastolic dysfunction. Global longitudinal strain and cardiopulmonary exercise testing results were similar in both patient groups. On multivariable Cox regression analysis, HF due to cancer therapy, compared with other HF patients, was associated with a higher risk of death (HR 2.64; 95\% CI 1.53 to $4.55 ; \mathrm{p}=0.001$ ) and the composite endpoint of LV assistant device implantation, heart transplantation or all-cause mortality (HR 1.79; 95\% CI 1.10 to $2.91 ; \mathrm{p}=0.019$ ) (figure 1 ).

Putting this study in context, Lyon ${ }^{1}$ points out the long interval (mean 10 years) between cancer therapy and clinical HF, the heterogeneous causes of $\mathrm{HF}$ in the comparison cohort, and the possibility that patients seen at a tertiary medical centre may have more advanced disease than in the general community. Even so, these data suggest that patients who present with HF late after cancer therapy have more severe $\mathrm{HF}$ and a poor prognosis. Looking ahead, he recommends that steps to prevent HF after cancer therapy should include (1) baseline CVD risk assessment, (2) close surveillance during therapy, (3) consideration of other options to reduce anthracycline cardiotoxicity, including

Correspondence to Professor Catherine M Otto, Division of Cardiology, University of Washington, Seattle WA 98195, USA; cmotto@uw.edu
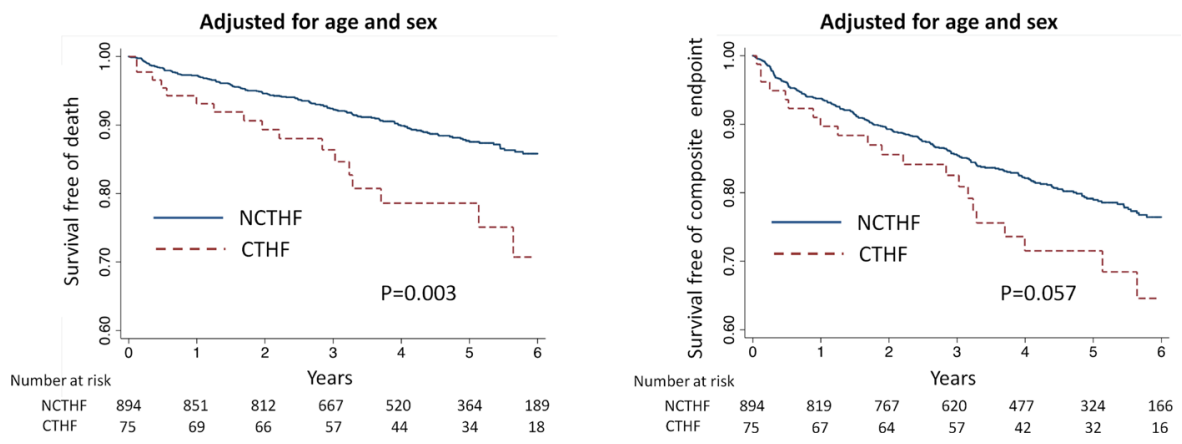

Figure 1 Kaplan-Meier curves for death and composite endpoint. The composite endpoint was defined as the composite outcome of left ventricular assistant device implantation, heart transplantation or all-cause mortality. CTHF, cancer therapy-induced heart failure; NCTHF, noncancer therapy-induced heart failure.

lower doses or alternate agents and (4) routine long-term CVD surveillance after completion of cancer therapy.' ${ }^{3}$ 'Education of survivors to recognise cardiac symptoms and seek medical attention, and education of primary care physicians to consider cardiac late effects in cancer survivors are also important.' Even with newer cancer therapies, cardiotoxicity remains a clinical problem. ${ }^{4}$

There has been great interest in the idea that patients would be more likely to consistently take medications for CVD prevention if combined in a single pill that combines or a 'polypill'. In a meta-analysis of three randomised clinical trials

comparing single pill containing a statin, aspirin and an antihypertensive medication to usual care, Selak et $a l^{5}$ found that the polypill approach increased the number of patients achieving guideline targets for blood pressure (62\% vs 58\%, risk ratio (RR) $1.08,95 \%$ CI 1.02 to 1.15 ) and low-density lipoprotein (LDL) cholesterol (39\% vs 34\%, RR 1.13, 95\% CI 1.02 to 1.25$)$, as well as antiplatelet therapy in those with a prior CVD event. (figure 2) All three guideline targets were achieved in more patients with the polypill approach ( $24 \%$ vs $19 \%$ ), although it is puzzling that this effect was strongest in those taking fewer pills at baseline.
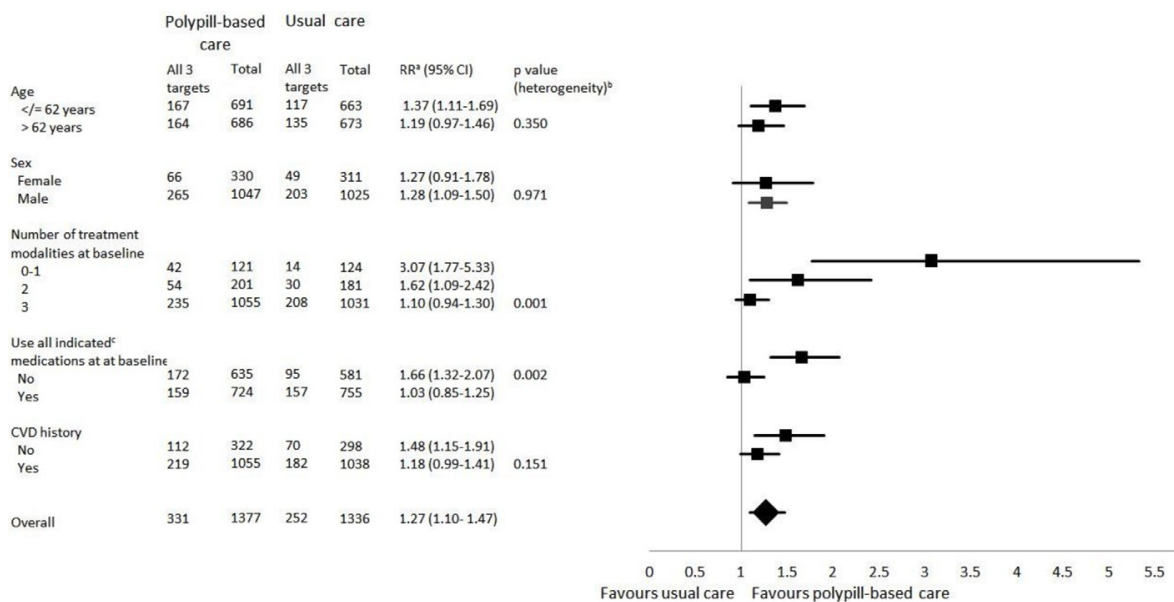

Figure 2 Achievement of all three ${ }^{d}$ treatment targets simultaneously at 12 months by subgroup. $a, b R$ and $p$ value (heterogeneity) estimated from log-binomial regression model. 'Statin, antiplatelet and >2 BP-lowering medications; all were indicated according to the participant's physician on trial entry. ${ }^{\mathrm{d}}$ Antiplatelet target only applicable to people with established CVD. BP, blood pressure; CVD, cardiovascular disease; RR, risk ratio. 


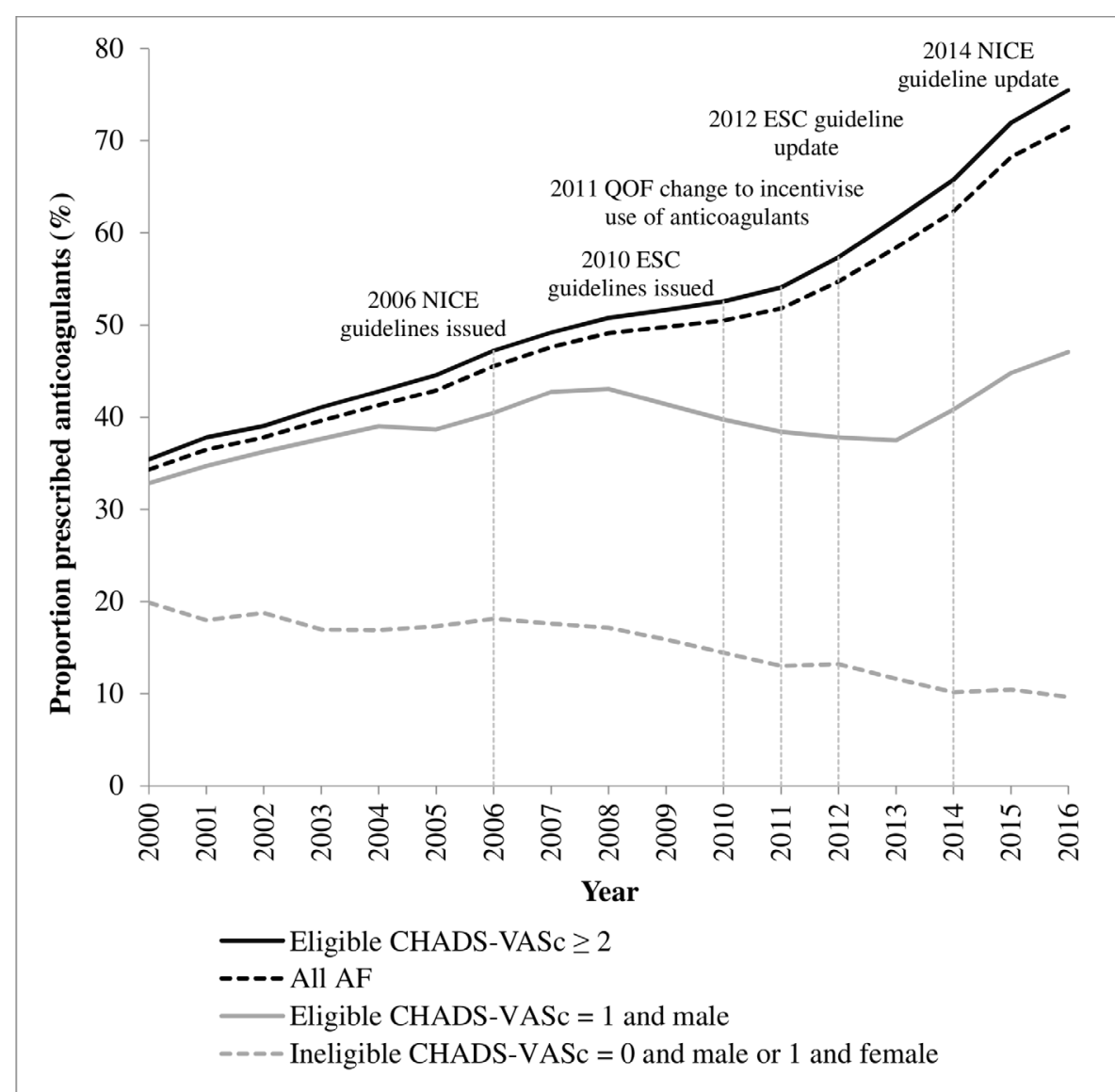

Figure 3 Proportion of patients with AF prescribed anticoagulants stratified by $\mathrm{CHA}_{2} \mathrm{DS}_{2}$-VASC score, 2000-2016. AF, atrial fibrillation; ESC, European Society of Cardiology; NICE, National Institute for Health and Care Excellence; QOF, Quality and Outcomes Framework.

Ibañez et $a l^{6}$ point out that while patients with an acute CVD event now are likely to survive, there is a high risk of recurrent events, with about $9 \%$ of those events related to poor adherence to medical therapy. Recent studies show that major adverse CVD events are significantly lower in patients who actually take their medications so there clearly is a need

to consider strategies to improve adherence. They conclude that 'there is robust evidence that the use of a cardiovascular polypill strategy results in increased adherence to treatments, to better control modifiable risk factors and to a higher proportion of patients meeting European Society of Cardiology guideline targets for LDL cholesterol and blood pressure.

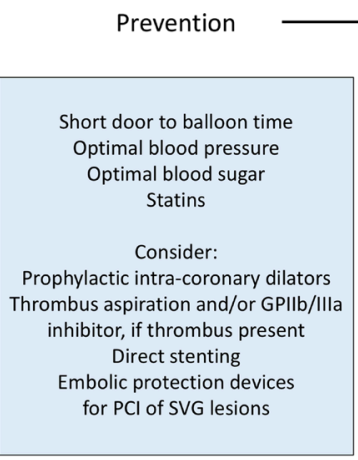

Although there are still no data showing that these benefits translate into a reduction in hard endpoints, adoption of this strategy can now be considered in daily practice.'

Another paper in this issue of Heart used a large electronic primary care database in the UK to show that the age-standardised and sex-standardised prevalence of atrial fibrillation (AF) increased from about $2 \%$ in 2000 to over $3 \%$ in $2016{ }^{7}$ Over this time period the proportion of patients with AF treated with anticoagulants increased from $35 \%$ to $76 \%$ in those at high risk of stroke and from $33 \%$ to $47 \%$ in those at moderate risk of stroke. Conversely, use of anticoagulants appropriately decreased from $20 \%$ to $10 \%$ in patients with AF at low risk of stroke (figure 3). What accounts for this remarkable improvement in stroke prevention in patients with AF? Sandhu and Ezekowitz ${ }^{8}$ suggest several possible explanations, in addition to guideline changes, including the availably of newer oral anticoagulant medications, financial incentives for optimal AF management, integration of guidelines in clinical flow and use of standardised order forms. Going forward, they argue that 'additional simple and cost-effective strategies are needed to demonstrate an even higher use of direct oral anticoagulant (DOAC) in eligible patients, particularly those at moderate risk, minimise overtreatment and reduce practice variations that can be implemented in different healthcare systems where incentivising may not be an option.'

The Education in Heart article in this issue focuses on complications of percutaneous coronary interventions with descriptions of common complications and a summary of strategies to avoid and treat complications to improve the overall safety of percutaneous coronary intervention $^{9}$ (figure 4).

The image challenge case in this issue will test your interpretation of the ECG and echocardiogram in a 76-year-old man with progressive dyspnoea. ${ }^{10}$

\section{Competing interests None declared.}

Patient consent for publication Not required.

Provenance and peer review Commissioned; internally peer reviewed.

(c) Author(s) (or their employer(s)) 2019. No commercial re-use. See rights and permissions. Published by BMJ.

\section{Check for updates}

To cite Otto CM. Heart 2019;105:1-3.

Heart 2019;105:1-3.

doi:10.1136/heartjnl-2018-314538
Figure 4 Management of no-reflow. ACT, activated clotting time; GPIlb/llla, glycoprotein Ilb/ percutaneous coronary intervention; SVG, saphenous vein graft. 


\section{REFERENCES}

1 Lyon AR. Heart failure resulting from cancer treatment: still serious but an opportunity for prevention. Heart 2019;105:6-8.

2 Nadruz W, West E, Sengeløv M, et al. Cardiovascular phenotype and prognosis of patients with heart failure induced by cancer therapy. Heart 2019;105:34-41.

3 Henriksen PA. Anthracycline cardiotoxicity: an update on mechanisms, monitoring and prevention. Heart 2019;104:971-7.

4 Dobbin SJH, Cameron AC, Petrie MC, et al. Toxicity of cancer therapy: what the cardiologist needs to know about angiogenesis inhibitors. Heart 2018:1995-2002.

5 Selak V, Webster R, Stepien S, et al. Reaching cardiovascular prevention guideline targets with a polypill-based approach: a meta-analysis of randomised clinical trials. Heart 2019; 105:42-8.

6 Ibañez B, Castellano JM, Fuster V. Polypill strategy at the heart of cardiovascular secondary prevention. Heart 2019:105:9-10.

7 Adderley NJ, Ryan R, Nirantharakumar K, et al. Prevalence and treatment of atrial fibrillation in
UK general practice from 2000 to 2016. Heart 2019;105:27-33.

8 Sandhu RK, Ezekowitz JA. Is incentivising stroke prevention therapy in atrial fibrillation the key? Heart 2019;105:4-5.

9 Kandan SR, Johnson TW. Management of percutaneous coronary intervention complications. Heart 2019;105:75-86.

10 Martínez-Milla J, Maestre Bastardo ÁJ, Cortés M. Seventy-six-year-old man with progressive dyspnoea. Heart 2019;105:74. 